\title{
The prognostic value of serum C-reactive protein-bound serum amyloid $A$ in early-stage lung cancer
}

\author{
Xue-Yan Zhang 1,2,3, Ge Zhang ${ }^{4}$, Ying Jiang ${ }^{5}$, Dan Liu ${ }^{1,6}$, Man-Zhi Li ${ }^{1,2}$, Qian Zhong ${ }^{1,2}$, Shan-Qi Zeng ${ }^{7}$, \\ Wan-Li Liu ${ }^{1,6^{*}}$ and Mu-Sheng Zeng ${ }^{1,2^{*}}$
}

\begin{abstract}
Background: Elevated levels of serum C-reactive protein (CRP) have been reported to have prognostic significance in lung cancer patients. This study aimed to further identify CRP-bound components as prognostic markers for lung cancer and validate their prognostic value.

Methods: CRP-bound components obtained from the serum samples from lung cancer patients or healthy controls were analyzed by differential proteomics analysis. CRP-bound serum amyloid A (CRP-SAA) was evaluated by coimmunoprecipitation (IP). Serum samples from two independent cohorts with lung cancer (retrospective cohort, 242 patients; prospective cohort, 222 patients) and healthy controls (159 subjects) were used to evaluate the prognostic value of CRP-SAA by enzyme-linked immunosorbent assay.

Results: CRP-SAA was identified specifically in serum samples from lung cancer patients by proteomic analysis. CRP binding to SAA was confirmed by co-IP in serum samples from lung cancer patients and cell culture media. The level of CRP-SAA was significantly higher in patients than in healthy controls $(0.37 \pm 0.58 \mathrm{vs} .0 .03 \pm 0.04, P<0.001)$. Elevated CRP-SAA levels were significantly associated with severe clinical features of lung cancer. The elevation of CRPSAA was associated with lower survival rates for both the retrospective (hazard ration [HR] $=2.181,95 \%$ confidence interval $[\mathrm{Cl}]=1.641-2.897, P<0.001)$ and the prospective cohorts $(\mathrm{HR}=2.744,95 \% \mathrm{Cl}=1.810-4.161, P<0.001)$. Multivariate Cox analysis showed that CRP-SAA was an independent prognostic marker for lung cancer. Remarkably, in stages I-II patients, only CRP-SAA, not total SAA or CRP, showed significant association with overall survival in two cohorts. Moreover, univariate and multivariate Cox analyses also showed that only CRP-SAA could be used as an independent prognostic marker for early-stage lung cancer patients.
\end{abstract}

Conclusion: CRP-SAA could be a better prognostic marker for lung cancer than total SAA or CRP, especially in earlystage patients.

Keywords: Serum C-reactive protein-bound serum amyloid A, Lung cancer, Prognostic marker, Proteomic analysis

\section{Background}

Lung cancer is the most common cause of cancer-associated death worldwide [1]. In China, the incidence and mortality of lung cancer are the highest among all cancers [2-4]. Early diagnosis and appropriate treatment are

\footnotetext{
*Correspondence: liuwl@sysucc.org.cn; zengmsh@sysucc.org.cn 'State Key Laboratory of Oncology in South China, Collaborative Innovation Center for Cancer Medicine, Sun Yat-sen University Cancer Center, Guangzhou, Guangdong 510060, P.R. China

Full list of author information is available at the end of the article
}

key factors for the improvement of prognosis. Predictive and prognostic biomarkers are needed to divide earlystage lung cancer patients into subgroups [5] and can improve medical decision-making in delivering the most suitable treatment.

Recently, chronic inflammation has been found to be associated with tumor progression, and many inflammatory factors could serve as prognostic biomarkers for some tumors $[6,7]$. Lung cancer presents as a chronic inflammatory disease $[8,9]$. Several studies have 
suggested that the elevation of serum $\mathrm{C}$-reactive protein (CRP) could be used as a prognostic factor for lung cancer [10-12].

CRP, a classical member of the pentraxin family, has high affinity for many types of autologous and extrinsic ligands. Autologous ligands include damaged cell membranes, apoptotic cells, plasma lipoproteins, phospholipids, ribonucleoprotein particles, extracellular matrix proteins, and $\mathrm{Fc}-\gamma$ receptors. Extrinsic ligands include various constituents of many microorganisms. Once aggregated or bound to macromolecular ligands, CRP activates the complement system to form membrane attack complex, which in turn attacks target molecules or cells. Therefore, CRP plays a key scavenger role in the clearance of abnormal cells or apoptotic cells [13, 14]. CRP is secreted by hepatocytes in response to the inflammatory cytokines produced by the tumor microenvironment [15], and CRP can enter the tumor microenvironment through the circulation, where it binds to a variety of autologous and extrinsic ligands and plays a key role in the clearance of tumor cells [16].

As CRP has the ability to bind to various ligands, a subset of the circulating CRP pool may exist in the form of CRP complexes. Because elevated circulating levels of CRP have been frequently found in lung cancer patients [10-12], we hypothesized that CRP may bind to ligands expressed by lung cancer cells or tumor-associated cells and that CRP-bound components in the serum of lung cancer patients may be different from those of healthy subjects. Therefore, CRP-bound complexes in the serum may be potential prognostic biomarkers of lung cancer.

In an effort to identify possible novel biomarkers to further refine the prognostic prediction accuracy of serum CRP levels for lung cancer, we used differential proteomics technology to identify a specific type of CRP complex in serum samples from lung cancer patients. We also evaluated the value of this CRP complex as a potential prognostic marker in two independent cohorts of lung cancer patients.

\section{Methods}

\section{Patients and serum samples}

Serum samples were collected from two independent cohorts of lung cancer patients recruited from the Sun Yat-sen University Cancer Center (SYSUCC). Patients recruited for the retrospective cohort $(n=242)$ were first diagnosed and treated between 2002 and 2004, and follow-up data from these patients were available up to 2010. Patients recruited for the prospective cohort $(n=222)$ were first diagnosed and treated between 2008 and 2010, and they were followed up to 2014. Detailed patient characteristics are described in Table 1. Serum samples were also obtained from 159 healthy controls
Table 1 Clinical characteristics of the recruited patients with lung cancer

\begin{tabular}{lll}
\hline Characteristic & Retrospective cohort & Prospective cohort \\
\hline $\begin{array}{l}\text { Total (cases) } \\
\text { Sex [cases (\%)] }\end{array}$ & 222 & 242 \\
Male & $169(76.1)$ & $176(72.7)$ \\
Female & $53(23.9)$ & $66(27.3)$ \\
Age (years) & & \\
Median & 59 & 59 \\
Range & $28-91$ & $31-79$ \\
Tumor clinical stage ${ }^{\text {a }}$ [cases (\%)] & \\
I & $37(16.6)$ & $39(16.1)$ \\
II & $43(19.4)$ & $40(32.6)$ \\
III & $71(32.0)$ & $99(40.9)$ \\
IV & $71(32.0)$ & $64(26.4)$ \\
\hline
\end{tabular}

Patient characteristics were recorded at the time point of blood withdrawal for serum analysis.

a Tumor staging was performed according to the seventh edition of the International Lung Cancer Staging published by the Union for International Cancer Control (UICC) and International Association for the Study of Lung Cancer (IASLC).

recruited from SYSUCC staff volunteers between 2008 and 2010.

The selection criteria for lung cancer patients were as follows: histologically confirmed lung cancer, complete documentation of medical history, primary lung cancer features and disease course, completeness of follow-up examinations, and absence of systemic treatment for at least 6 weeks before blood withdrawal. Clinical stage was assessed according to the seventh edition of the Lung Cancer Staging International Division, which was published by the Union for International Cancer Control (UICC) and the International Association for the Study of Lung Cancer (IASLC) in 2009. To use these serum samples for research purposes, prior informed consent from the patients and approval from the Institute Research Ethics Committee of SYSUCC were obtained. The selection criteria for healthy controls were as follows: good physical status, no acute or chronic disease, and not taking any medication.

Serum samples were collected and processed at SYSUCC Biobank according to standard procedures. In brief, venous blood was drawn into serum tubes, clotted at room temperature for $1 \mathrm{~h}$, and subsequently centrifuged at 2,500 $\times g$ for $10 \mathrm{~min}$. Serum was collected, distributed into $100 \mu \mathrm{L}$ aliquots, and immediately stored at $-80^{\circ} \mathrm{C}$. Repeated freeze-thaw cycles were avoided for all serum samples.

\section{Serum proteomic profiling} CRP complex purification from mixed serum

Serum samples from 10 lung cancer patients and from 10 healthy controls were mixed, respectively. CRP complexes were purified from the mixed cancer serum or 
mixed control serum using the following method. In brief, after centrifugation at $10,000 \times g$ for $10 \mathrm{~min}$ at $4^{\circ} \mathrm{C}, 500 \mu \mathrm{L}$ of serum was diluted in $500 \mu \mathrm{L}$ of buffer $(20 \mathrm{mmol} / \mathrm{L}$ Tris-HCl, $150 \mathrm{mmol} / \mathrm{L} \mathrm{NaCl}, 5 \mathrm{mmol} / \mathrm{L}$ $\mathrm{CaCl}_{2}, 0.1 \%$ Nonidet P-40, $\mathrm{pH} 7.4$ ), and CRP complexes were precipitated by shaking overnight at $4^{\circ} \mathrm{C}$ using $500 \mu \mathrm{L}$ of anti-CRP carboxyl-coated polyethylene beads (Stagnant Water Co., Osaka, Japan). The beads were washed 5 times with dilution buffer by centrifugation at $10,000 \times g$ for $10 \mathrm{~min}$ at $4^{\circ} \mathrm{C}$, and the supernatant with unbound proteins was removed. The pellets were solubilized in $100 \mu \mathrm{L}$ of triethyl-ammonium bicarbonate (TEAB) lysis buffer $(20 \mathrm{mmol} / \mathrm{L}$ TEAB, $20 \mathrm{mmol} / \mathrm{L}$ DLdithiothreitol [DTT], $1 \%$ sodium dodecyl sulfate [SDS]) at room temperature for $10 \mathrm{~min}$, heated to $95^{\circ} \mathrm{C}$ for $10 \mathrm{~min}$, and then allowed to cool for a further $10 \mathrm{~min}$ at room temperature. Samples containing the affinity-purified proteins were subjected to an additional centrifugation step $(10,000 \times g$ for $30 \mathrm{~min}$ at room temperature), and the supernatants were collected.

\section{Sodium dodecyl sulfate-polyacrylamide gelelectrophoresis (SDS-PAGE) and liquid chromatograph-mass spectrometry/ mass spectrometry (LC-MS/MS) analysis}

The affinity-purified proteins were applied to $8 \%-14 \%$ gradient gels for SDS-PAGE. After staining with $0.5 \%$ Coomassie brilliant blue G-250, the lane with a molecular weight of approximately $12 \mathrm{kDa}$, which was only present in serum from lung cancer patients and not in healthy control serum, was excised and subjected to in-gel tryptic digestion. After in-gel digestion with trypsin, the extracted peptide mixtures were loaded onto a nanoscale LC-ESI-Q-TOF MS instrument (Q-TOF Micromass Spectrometer, Waters Co., Milford, MA, USA) for protein identification. All data generated from the gel section were used to search the international protein index (IPI) human database (v3.61) using Paragon Algorithm 21, which is integrated into the Protein Pilot search engine (v.3; AB SCIEX, Foster, CA, USA).

\section{Two-dimensional electrophoresis (2-DE) and matrix-assisted laser desorption ionization time of flight/time of flight mass spectrometry (MALDI TOF/TOF MS) analysis}

Affinity-purified CRP complexes were subjected to twodimensional separation, and 2-DE runs were repeated three times. After electrophoresis, the gels were stained with blue silver, scanned in a densitometer (Molecular Imager FX, BioRad company, Hercules, CA, USA) at a resolution of $600 \mathrm{dpi}$, and analyzed using PDQuest software (version 7.1.0, BioRad). Protein spots exhibiting twofold or higher change in density (Student's $t$ test, $P<0.05)$ in a consistent direction were considered to be different and selected for further identification.

\section{Peptide extraction}

Protein spots of interest were in-gel digested by trypsin. Gel pieces were first discolored in 50\% acrylonitrile $(\mathrm{ACN})$ and $25 \mathrm{mmol} / \mathrm{L}$ ammonium bicarbonate and subsequently subjected to reduction in $10 \mathrm{mmol} / \mathrm{L}$ DTT and alkylation in $55 \mathrm{mmol} / \mathrm{L}$ iodoacetic acid. Following vacuum drying, the gel pieces were incubated with sequencing grade modified trypsin (Promega Co., Madison, WI, USA) at a final concentration of $0.01 \mathrm{mg} / \mathrm{mL}$ in $25 \mathrm{mmol} / \mathrm{L}$ ammonium bicarbonate for $16 \mathrm{~h}$ at $37^{\circ} \mathrm{C}$. Supernatants were collected, vacuum-dried, and re-dissolved in 50\% ACN and 0.1\% trifluoroacetic acid (TFA) for MS analysis.

\section{MALDI TOF/TOF analysis}

Tryptic peptides were finally dissolved in MALDI matrix (7 $\mathrm{mg} / \mathrm{mL} \alpha$-cyano-4-hydroxycinnamic acid in $0.1 \%$ TFA and $50 \% \mathrm{ACN}$ ), spotted onto 192-well stainless steel MALDI target plates, and analyzed using an ABI 4800 Proteomics Analyzer MALDI TOF/TOF mass spectrometer (Applied Biosystems, Carlsbad, CA, USA). The MS together with the MS/MS spectra were searched against the IPI Human database version 3.24 using GPS ExplorerTM Version 3.0 software and MASCOT database search algorithms (version 2.0). The following search criteria were used: trypsin specificity, cysteine carbamidomethylation $(\mathrm{C})$, and methionine oxidation $(\mathrm{M})$ as variable modifications, 1 trypsin miscleavage allowed, 100 ppm MS tolerance, and 0.25 Da MS/MS tolerance. All identified proteins had protein scores greater than 59 $(P<0.05)$ and individual ion scores greater than 21 with expected values $(P<0.05)$. All MS/MS spectra were further validated manually.

Co-immunoprecipitation (IP) of CRP-bound serum amyloid A (SAA) complexes from serum samples and cell culture media

\section{CRP-SAA complex expression in cell culture media}

293FT cells were maintained in our lab and cultured in dulbecco's modified eagle medium (DMEM) (Gibco, Grand Island, NY, USA) supplemented with $10 \%$ fetal bovine serum (Gibco) and 1\% penicillin/streptomycin (Gibco). For transfections, we used the pSPHis plasmid vector, pSPHis-CRP, and pSPHis-SAA recombinant plasmid which were all constructed and preserved by our laboratory, and these plasmids can effectively express secreted proteins from inserted gene fragments. A CRPsecreting 293FT stable cell line (293FT-CRP) was established through transfection of the pSPHis-CRP plasmid, and a SAA-secreting 293FT stable cell line (293FT-SAA) was established by transfection with the pSPHis-SAA plasmid. The 293FT-CRP and 293FT-SAA cell lines were mixed in equivalent numbers for culture. After 
incubation for $24 \mathrm{~h}$, cells were washed twice with serumfree DMEM, then further incubated for $48 \mathrm{~h}$ in serumfree DMEM. The cell culture media were collected and centrifuged at $2,000 \times g$ for $20 \mathrm{~min}$, and the supernatants, which contained CRP-SAA complexes, were collected.

\section{Co-IP of CRP-SAA complexes}

Similar to the method for purification of CRP complexes, the CRP-SAA complexes from the serum samples or the cell supernatants were evaluated by IP using anti-CRP carboxyl-coated polyethylene beads (Stagnant Water Co.), followed by immunoblotting with anti-SAA polyclonal antibody (sc-20651, Santa Cruz, Dallas, TX, USA). The CRP-SAA complexes were also evaluated by IP with anti-SAA polyclonal antibody and protein A/G beads (20423, Pierce, Rockford, IL, USA), and immunoblotting with an anti-CRP antibody (ab13426, Abcam, Cambridge, UK).

\section{Western blotting}

Purified CRP complexes were resolved using 12\% SDSPAGE. The proteins were then transferred to polyvinylidene difluoride (PVDF) membranes and incubated with anti-SAA or anti-CRP antibodies after blocking. The membrane was washed with phosphate-buffered saline with tween (PBST) and then incubated with horseradish peroxidase-conjugated secondary antibodies (Pierce) prior to visualization of the bands using enhanced chemiluminescence western blotting substrate (32106, Pierce).

\section{Immunohistochemical assay}

Anti-SAA polyclonal rabbit antibody was used as the primary antibody. The immunohistochemical kit (SP-9001 rabbit SP kit, 50581654) was obtained from Zhongshan Golden Bridge Co. Ltd. (Beijing, China). The anti-SAA polyclonal antibody was incubated overnight at $4^{\circ} \mathrm{C}$. After washing with phosphate-buffered saline (PBS), the biotinylated secondary antibody of the kit was applied for $15 \mathrm{~min}$ at $37^{\circ} \mathrm{C}$. Then, the sections were incubated with streptavidin-horseradish peroxidase complex and developed with $3^{\prime}$-diaminobenzidine tetrahydrochloride (DAB). Light Mayer's hematoxylin (Zhongshan Golden Bridge) was applied as a counterstain.

\section{Enzyme-linked immunosorbent assay (ELISA)}

To detect CRP-bound SAA (CRP-SAA) or total SAA, 96-well ELISA plates (Corning, Corning, NY, USA) were coated with $0.5 \mu \mathrm{g} / \mathrm{mL}$ anti-CRP monoclonal antibody (DY1707, R\&D, Minneapolis, MN, USA) or $100 \mathrm{ng} / \mathrm{well}$ anti-SAA polyclonal antibody in $0.05 \mathrm{~mol} / \mathrm{L} \mathrm{NaHCO}_{3}$, $\mathrm{pH} 9.0$, overnight at $4^{\circ} \mathrm{C}$, followed by blocking with $3 \%$ bovine serum albumin in $\mathrm{PBS}$ for $3 \mathrm{~h}$ at $37^{\circ} \mathrm{C}$. Serum samples were tested in duplicate; they were diluted at 1:100 with Signal Boost Solution 1 (407207, Merck Calbiochem, Darmstadt, Hesse, Germany) and incubated for $2 \mathrm{~h}$ at $37^{\circ} \mathrm{C}$. After four washes with PBST, the plates were incubated with 1:6,000 diluted biotin-labeled antiSAA monoclonal antibody (LS-C20534, LifeSpan BioSciences, Seattle, WA, USA) in Signal Boost Solution 2 (407207, Merck Calbiochem) for another $2 \mathrm{~h}$ at $37^{\circ} \mathrm{C}$. The plates were then incubated with 1:5,000 HRP-labeled avidin (43-4323, Invitrogen, Carlsbad, CA, USA). After four washes with PBST, color was developed using tetramethyl benzidine substrate, and the optical density (OD) at $450 \mathrm{~nm}$ was measured. Every serum sample was tested three times, and the average OD value was recorded.

For the detection of serum CRP, we chose the classic quantitative method. Serum CRP was measured by particle-enhanced immunoturbidimetry (Wako, Osaka, Japan) using a Hitachi 2008 system (Hitachi, Tokyo, Japan).

\section{Statistical analysis}

Statistical analyses were mainly conducted using the SPSS 16.0 statistical software package (SPSS Inc., Chicago, IL, USA). Receiver operating characteristic (ROC) curve analyses were used to compare the sensitivity and specificity for the detection of CRP-SAA and total SAA. The Mann-Whitney $U$ test was used to analyze associations between the levels of CRP-SAA, total SAA and clinical characteristics. Survival curves were plotted using the Kaplan-Meier method and compared using the logrank test. The significance of various variables in survival outcomes was assessed by applying the Cox proportional hazards model to the univariate and multivariate analyses. $P<0.05$ was considered significant in all cases.

\section{Results}

\section{Identification of CRP-SAA complexes in the serum of lung} cancer patients

CRP-bound components in serum samples obtained from healthy controls or lung cancer patients were purified using anti-CRP carboxyl-coated polyethylene beads and subjected to SDS-PAGE. Gel bands show a mass of 12-14 kDa, indicating CRP complexes, in the serum samples from lung cancer patients but not in healthy control samples (Fig. 1a). These bands were selected for protein identification. The SAA peptide fragments (SAA1/SAA2) were frequently identified in subsequent LS-MS/MS analysis and covered $69.7 \%$ of the amino acid sequences of SAA (IPI00552578). These data suggested that CRP formed a complex with SAA in the serum samples from lung cancer patients.

For further confirmation, serum CRP-bound components from healthy controls or lung cancer patients were 

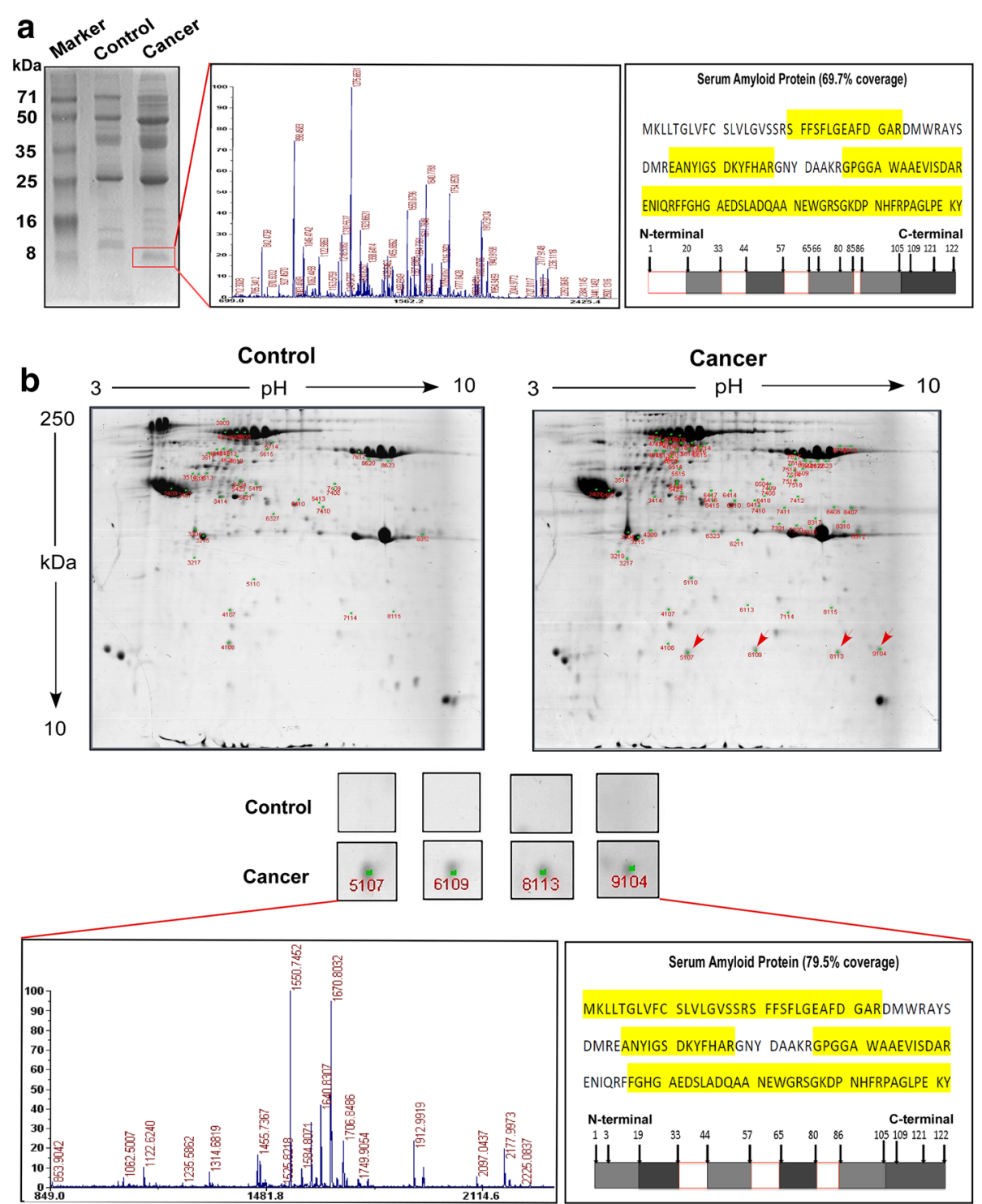

Fig. 1 Identification of serum C-reactive protein-bound serum amyloid A (CRP-SAA) complexes in serum samples from lung cancer patients. a Sodium dodecyl sulfate-polyacrylamide gelelectrophoresis (SDS-PAGE) and mass spectrometry (MS) of serum samples from healthy controls and lung cancer patients. The red frame indicates the discrepant bands. b Analysis of discriminative masses between normal and cancer serum samples through two-dimensional electrophoresis (2-DE) and MS. The red arrows indicate the discrepant masses corresponding to SAA1/SAA2 proteins.

evaluated using 2-DE. The protein spots with discrepancies between healthy controls and lung cancer patients were analyzed using MALDI TOF/TOF MS (Fig. 1b). CRP-bound components with significant differential expression (twofold or more change, $P<0.05$, Student's $t$-test) in the serum samples from lung cancer patients are shown in Table 2. SAA1/SAA2 (IPI00552578) and SAA2 isoform A (IPI00006146) exhibited 79.5\% amino acid sequence coverage in the MS analysis (Fig. 1b). Because the protein homology between SAA1 and SAA2 is $95.9 \%$, we hereafter used SAA to indicate both SAA1 and SAA2.
Confirmation of CRP-SAA complexes in serum samples or cell culture media and expression of SAA in lung cancer tissues

SAA is known as an acute-phase protein and has been reported to be elevated in the serum of lung cancer patients [17]. We detected the existence of CRP-SAA in the mixed serum sample from 10 lung cancer patients on which we previously performed the proteomics analysis (Fig. 2a) and some serum samples from individual lung cancer patients (Fig. 2b) by co-IP. The property of CRP binding to SAA was also confirmed in the media from 


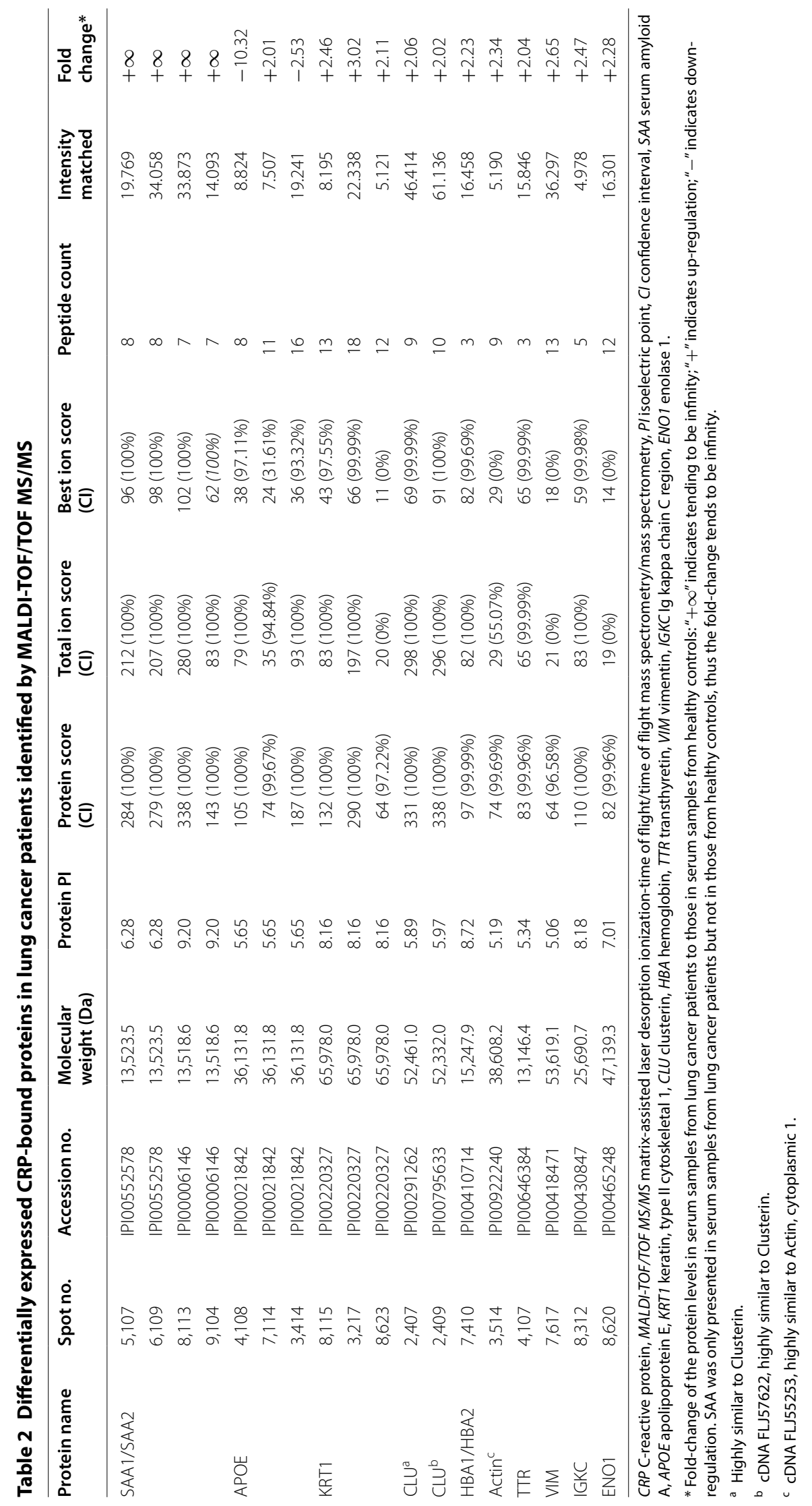




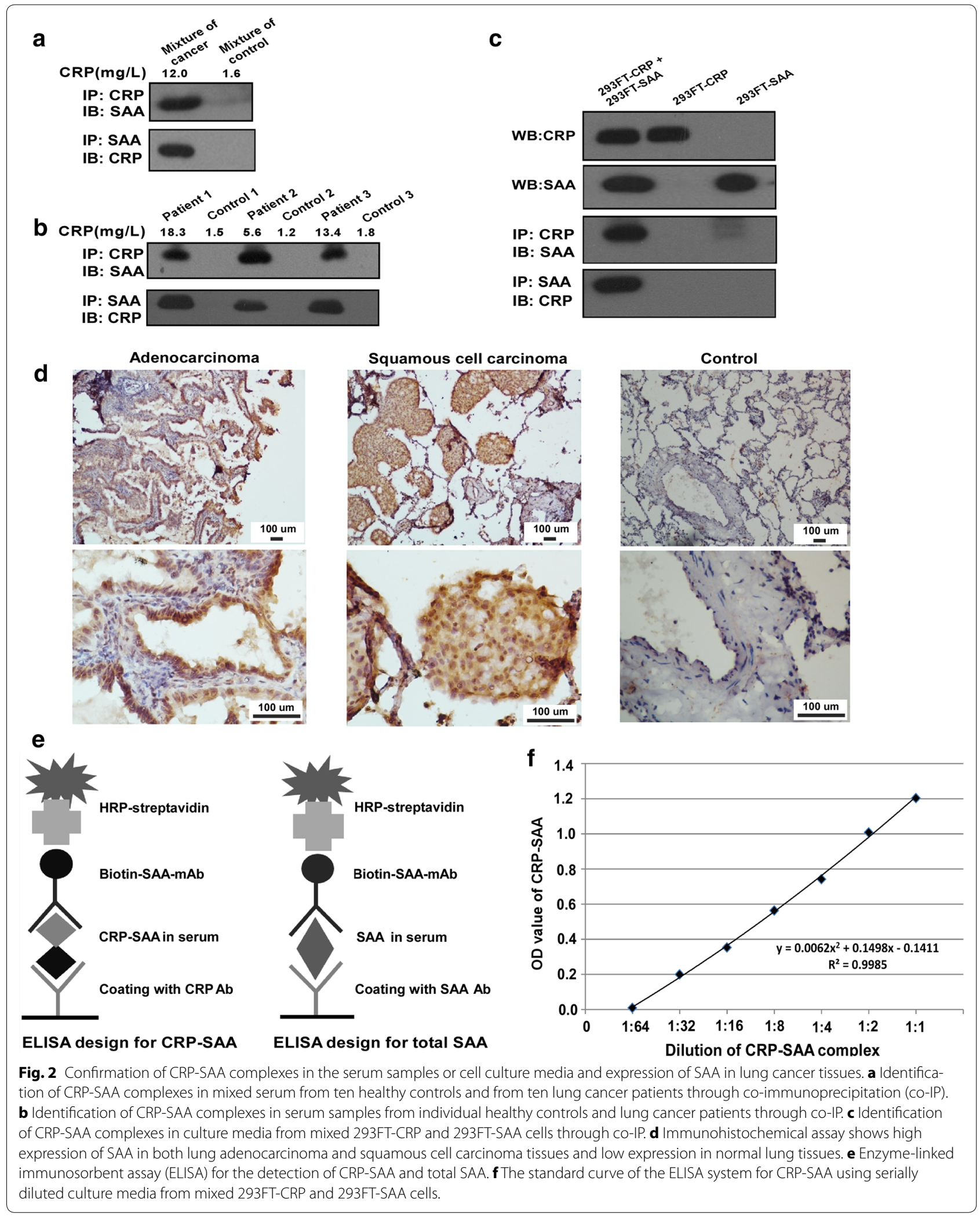


mixed cultivation of the 293FT-CRP and 293FT-SAA cell lines (Fig. 2c).

Recently, it was reported that melanoma cells can produce SAA, although SAA is typically known as a primary product of hepatocytes [18]. We found that SAA was highly expressed in lung cancer tissue but expressed at low levels in normal lung tissues (Fig. 2d).

Next, we investigated whether CRP-SAA or total SAA in serum could be used as a lung cancer marker. We established two ELISA systems: one to detect total SAA, in which two different SAA antibodies were used in coating and detection, and another to detect CRP-SAA, in which anti-CRP antibodies were used to capture CRP complexes and biotin-labeled anti-SAA antibodies were used to detect CRP-SAA (Fig. 2e).

To evaluate the efficacy of the ELISA for CRP-SAA detection, mixed culture media of 293FT-CRP and 293FTSAA cells were diluted serially to prepare a standard curve for ELISA of CRP-SAA. The R value of the standard curve was $0.998,5$, indicating that this ELISA system can effectively determine the levels of CRP-SAA (Fig. 2f).

\section{Association of elevated serum CRP-SAA level with clinical features of lung cancer}

The serum levels of CRP-SAA and total SAA were evaluated in samples from two independent cohorts of lung cancer patients and healthy control samples using the two ELISA systems. Similar to total SAA, the serum levels of CRP-SAA in patients with lung cancer were elevated significantly compared with those in healthy controls $(P<0.001)$ (Fig. 3a). ROC analysis showed that the area under the ROC curve (AUC) for CRP-SAA in the diagnosis of lung cancer was 0.903, which was higher than the AUC of 0.845 obtained for total SAA (Fig. 3b). In addition, patients with advanced-stage cancers had higher levels of CRP-SAA and total SAA compared with those with early-stage cancers (Fig. 3c).

ROC analysis showed that ODs of 0.10 for CRP-SAA and 0.17 for total SAA were the optimal cutoff values to divide patients into low-level and high-level groups, respectively. Statistical analysis of clinical data between the low- and high-level groups of lung cancer patients revealed that the serum levels of CRP-SAA were closely associated with sex, smoking status, tumor size, lymph node involvement, distant metastasis, and clinical stage (Table 3). Similar to total SAA, high levels of CRP-SAA indicated severe clinical features.

\section{Prognostic value of CRP-SAA in the retrospective cohort of lung cancer patients}

We evaluated whether CRP-SAA could be a prognostic marker for lung cancer. In the retrospective cohort, patients with high levels of CRP-SAA showed a shorter median survival than those with low levels of CRP-SAA (Fig. 4a). The 5-year overall survival (OS) rate was lower in the high-level group than in the low-level group $(9.5 \%$ vs. $29.9 \%$ ). When patients were stratified by cancer stages, a high level of CRP-SAA was also associated with a shorter median survival in the stages I-II (Fig. 4b) and stages III-IV subgroups (Fig. 4c; Table 4).

Furthermore, the prognostic value of CRP-SAA was compared with those of total SAA and CRP. The cutoff value of CRP used for grouping was $8 \mathrm{mg} / \mathrm{L}$, as determined by ROC analysis. High levels of both total SAA and CRP were associated with shorter survival in the whole cohort and the stages III-IV subgroup, but not in the stages I-II subgroup; the 5-year OS rate was lower in the high-level group than in the low-level group for both total SAA (14.3\% vs. $27.6 \%)$ and CRP (9.6\% vs. $29.7 \%$ ) (Fig. 4d-i; Table 4).

\section{Prognostic value of CRP-SAA in an independent prospective cohort of lung cancer patients}

To confirm the prognostic value of CRP-SAA, we recruited an independent prospective cohort of patients and followed their survival for 4 years. Consistent with the results obtained from the retrospective cohort, high levels of CRP-SAA were associated with shorter survival in the whole prospective cohort, the stages I-II subgroup, and the stages III-IV subgroup; high levels of total SAA and CRP were associated with shorter survival in the whole prospective cohort and the stages III-IV subgroup, but not in the stages I-II subgroup (Fig. 5; Table 4).

\section{Potential prognostic value of CRP-SAA for lung cancer}

The results of univariate and multivariate Cox regression analyses of the prognostic values of various factors in the 464 lung cancer patients are presented in Tables 5 and 6. Multivariable analysis, adjusted for age, sex, smoking status, clinical stage, and treatment regimen, showed that CRP-SAA was an independent prognostic factor for OS in the whole cohort, the stages I-II subgroup, and the stages III-IV subgroup (all $P<0.005$ ); total SAA and CRP were also independent prognostic factors for OS in the whole cohort and the stages III-IV subgroup (all $P<0.005$ ), but not in the stages I-II subgroup (all $P>0.05$; Table 6).

\section{Discussion}

Through a differential proteomic analysis, we found that several proteins were significantly up-regulated in the form of CRP-bound complexes in the serum of lung cancer patients. SAA was exclusively presented in the form of CRP-bound complexes in the serum of lung cancer patients. Further in vitro studies confirmed that CRP could bind to SAA. SAA is known to be an acute-phase 

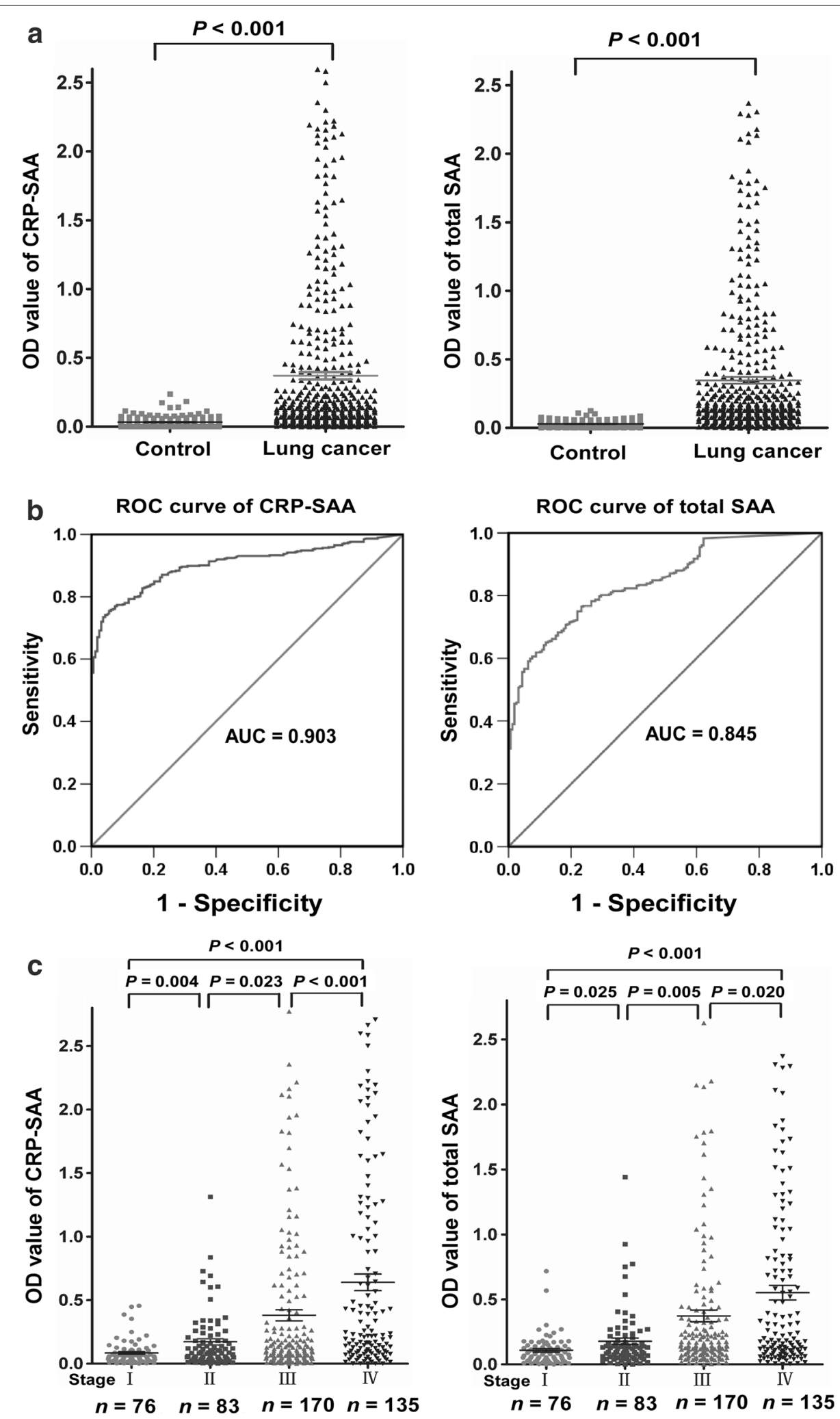

Fig. 3 CRP-SAA is a potential diagnostic marker for lung cancer. a The serum levels of both CRP-SAA and total SAA in lung cancer patients $(n=464)$ are elevated significantly compared with those in healthy controls $(n=159)$. b Receiver operating characteristic (ROC) curve analysis shows that the area under the ROC curve (AUC) is 0.903 for CRP-SAA and 0.845 for total SAA in the diagnosis of lung cancer. c Patients with advanced-stage cancers had higher levels of both CRP-SAA and total SAA compared with those with early-stage cancers. 
Table 3 Association between serum levels of CRP-bound SAA (CRP-SAA), total SAA and clinical characteristics of the 464 lung cancer patients

\begin{tabular}{|c|c|c|c|c|c|c|}
\hline \multirow[t]{2}{*}{ Characteristic } & \multicolumn{2}{|l|}{ CRP-SAA [cases (\%)] } & \multirow[t]{2}{*}{$P$ value } & \multicolumn{2}{|l|}{ Total SAA [cases (\%)] } & \multirow[t]{2}{*}{$P$ value } \\
\hline & Low level $(O D \leq 0.10)$ & High level $(O D>0.10)$ & & Low level $(O D \leq 0.17)$ & High level $(O D>0.17)$ & \\
\hline Total & 212 & 252 & & 271 & 193 & \\
\hline Age & & & 0.725 & & & 0.741 \\
\hline$<60$ years & $112(24.1)$ & $129(27.8)$ & & $139(30.0)$ & $102(22.0)$ & \\
\hline$\geq 60$ years & $100(21.6)$ & $123(26.5)$ & & $132(28.4)$ & $91(19.6)$ & \\
\hline Sex & & & 0.001 & & & 0.106 \\
\hline Male & $142(30.6)$ & $203(43.8)$ & & $194(41.8)$ & $151(32.5)$ & \\
\hline Female & $70(15.1)$ & $49(10.6)$ & & 77 (16.6) & $42(9.1)$ & \\
\hline Smoking status & & & $<0.001$ & & & $<0.001$ \\
\hline No & $113(24.4)$ & $85(18.3)$ & & $139(30.0)$ & $59(12.7)$ & \\
\hline Yes & $99(21.3)$ & $167(36.0)$ & & $132(28.4)$ & $134(28.9)$ & \\
\hline Treatment & & & $<0.001$ & & & $<0.001$ \\
\hline $\begin{array}{l}\text { Multimodality therapy } \\
\text { without operation }\end{array}$ & $86(18.5)$ & $54(11.6)$ & & $112(24.1)$ & $28(6.0)$ & \\
\hline Operation alone & $62(13.4)$ & $76(16.4)$ & & $82(17.7)$ & $56(12.1)$ & \\
\hline $\begin{array}{l}\text { Operation and } \\
\text { multimodality therapy }\end{array}$ & $64(13.8)$ & $122(26.3)$ & & $77(16.6)$ & $109(23.5)$ & \\
\hline Tstage & & & $<0.001$ & & & $<0.001$ \\
\hline $\mathrm{T} 1$ & $41(8.8)$ & $29(6.3)$ & & $54(11.6)$ & $16(3.4)$ & \\
\hline $\mathrm{T} 2$ & $109(23.5)$ & $100(21.6)$ & & $130(28.0)$ & $79(17.0)$ & \\
\hline $\mathrm{T} 3$ & $32(6.9)$ & $82(17.7)$ & & $51(11.0)$ & $63(13.6)$ & \\
\hline $\mathrm{T} 4$ & $30(6.5)$ & $41(8.8)$ & & $36(7.8)$ & $35(7.5)$ & \\
\hline N stage & & & $<0.001$ & & & $<0.001$ \\
\hline NO & $93(20.0)$ & $72(15.5)$ & & $113(24.4)$ & $52(11.2)$ & \\
\hline $\mathrm{N} 1$ & $33(7.1)$ & $41(8.8)$ & & $47(10.1)$ & $27(5.8)$ & \\
\hline N2 & $68(14.7)$ & $90(19.4)$ & & $84(18.1)$ & 74 (15.9) & \\
\hline N3 & $18(3.9)$ & $49(10.6)$ & & $27(5.8)$ & $40(8.6)$ & \\
\hline M stage & & & $<0.001$ & & & $<0.001$ \\
\hline MO & $174(37.5)$ & $155(33.4)$ & & $213(45.9)$ & $116(25.0)$ & \\
\hline M1 & $38(8.2)$ & $97(20.9)$ & & $58(12.5)$ & 77 (16.6) & \\
\hline Clinical stage & & & $<0.001$ & & & $<0.001$ \\
\hline I & $57(12.3)$ & $19(4.1)$ & & $61(13.1)$ & $15(3.2)$ & \\
\hline$\|$ & $41(8.8)$ & $42(9.1)$ & & $60(12.9)$ & $23(5.0)$ & \\
\hline III & $76(16.4)$ & $94(20.3)$ & & $92(19.8)$ & $78(16.8)$ & \\
\hline IV & $38(8.2)$ & $97(20.9)$ & & $58(12.5)$ & $77(16.6)$ & \\
\hline Pathologic type & & & 0.192 & & & 0.784 \\
\hline Adenocarcinoma & $112(24.1)$ & $131(28.2)$ & & $147(31.7)$ & $96(20.7)$ & \\
\hline Squamous cell carcinoma & $65(14.0)$ & $65(14.0)$ & & $72(15.5)$ & $58(12.5)$ & \\
\hline Small cell carcinoma & $15(3.2)$ & $33(7.1)$ & & $26(5.6)$ & $22(4.7)$ & \\
\hline Others & $20(4.3)$ & $23(5.0)$ & & $26(5.6)$ & $17(3.7)$ & \\
\hline Primary tumor site & & & 0.821 & & & 0.301 \\
\hline Left lung & $86(18.5)$ & $107(23.1)$ & & $105(22.6)$ & $88(19.0)$ & \\
\hline Right lung & $126(27.2)$ & 145 (31.3) & & 166 (35.8) & 105 (22.6) & \\
\hline
\end{tabular}

The Mann-Whitney $U$ test was used to analyze the associations. Tumor size, lymph node involvement, distant metastasis, and clinical stage were classified according to the seventh edition of the Union for International Cancer Control (UICC) Staging system for Lung Cancer.

$P<0.05$ is considered significant and the $P$-value is in italics.

$O D$ optical density. 


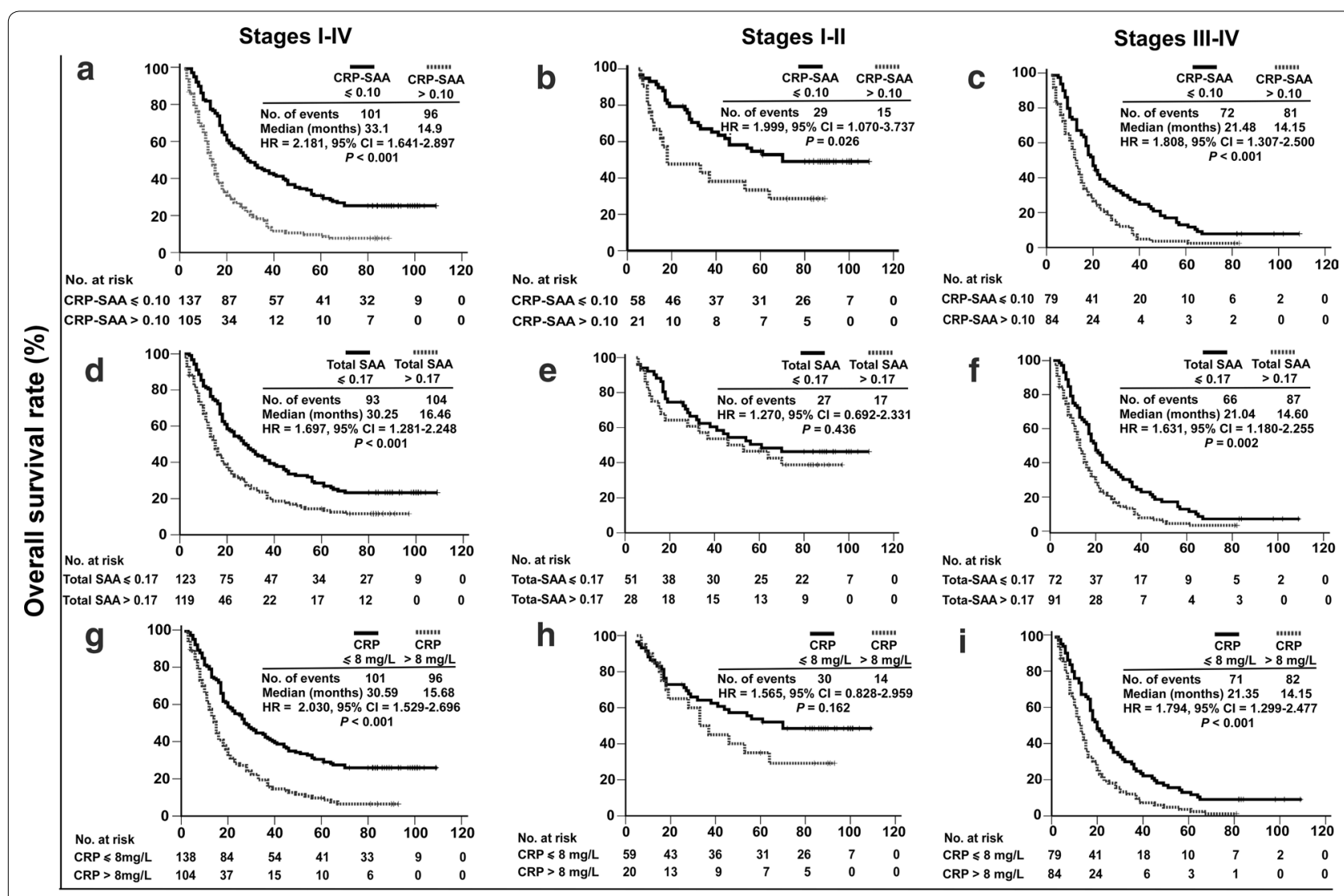

Time since blood withdrawal (months)

Fig. 4 Prognostic values of serum CRP-SAA, total SAA, and CRP in the retrospective cohort of lung cancer patients. a Kaplan-Meier survival curves of the 242 patients divided by the cutoff optical density (OD) value for CRP-SAA into low-level (OD $\leq 0.10)$ and high-level $(O D>0.10)$ groups. b Survival curves of 79 patients at stages I-II divided by the cutoff value for CRP-SAA into low- and high-level groups. c Survival curves of 163 patients at stages III-IV divided by the cutoff value for CRP-SAA into low- and high-level groups. $\mathbf{d}$ Survival curves of the 242 patients divided by the cutoff OD value for total SAA into low-level $(\mathrm{OD} \leq 0.17)$ and high-level $(\mathrm{OD}>0.17)$ groups. e Survival curves of 79 patients at stages I-II divided by the cutoff value for total SAA into low- and high-level groups. $\mathbf{f}$ Survival curves of 163 patients at stages III-IV divided by the cutoff value for total SAA into low- and high-level groups. $\mathbf{g}$ Survival curves of the 242 patients divided by the cutoff value for CRP into low-level (CRP $\leq 8 \mathrm{mg} / \mathrm{L})$ and high-level (CRP > $8 \mathrm{mg} / \mathrm{L}$ ) groups. h Survival curves of 79 patients at stages I-II divided by the cutoff value for CRP into low- and high-level groups. i Survival curves of 163 patients at stages III-IV divided by the cutoff value for CRP into low- and high-level groups. Significant differences were calculated using a log-rank test. The numbers of patients at risk at each specific time point are indicated. The number of events indicates the cumulative number of all events during the entire follow-up period. HR hazard ratio calculated by univariate Cox regression analysis, not adjusted by other factors. CI confidence interval.

protein and is more sensitive than CRP for predicting the prognosis of cancer. Recently, many reports have identified close relationships between elevated SAA in serum and worse prognoses of several types of cancers [19-22]. SAA was reported to be a potential diagnostic and prognostic biomarker for lung cancer [23, 24]. In our study, we first found that CRP bound to SAA and formed complexes in the serum of lung cancer patients. A sandwich ELISA was developed to detect serum CRP-SAA levels and evaluate their prognostic value.

Similar to total SAA, high levels of CRP-SAA were closely associated with the clinical features of lung cancer patients. Moreover, similar to total SAA and CRP, high levels of CRP-SAA were associated with shorter survival in both retrospective and prospective cohorts of lung cancer patients. Our data agree with the results of previous studies in which increased SAA and CRP levels were found to be useful biomarkers for the prediction of lung cancer prognosis $[17,24]$. Remarkably, in stages I-II patients, only CRP-SAA and not total SAA or CRP significantly predicted OS. Moreover, univariate and multivariate Cox analyses also showed that only CRP-SAA could be used as an independent prognostic marker for early-stage patients.

The performance of CRP-SAA in lung cancer prognosis may be related to its biological functions. The roles 
Table 4 Associations of CRP-SAA, total SAA, and CRP with survival of lung cancer patients in both the retrospective cohort and the prospective cohort

\begin{tabular}{|c|c|c|c|c|c|c|}
\hline \multirow[t]{2}{*}{ Variate } & \multicolumn{3}{|c|}{ The retrospective cohort } & \multicolumn{3}{|c|}{ The prospective cohort } \\
\hline & Stages I-IV & Stages I-II & Stages III-IV & Stages I-IV & Stages I-II & Stages III-IV \\
\hline \multicolumn{7}{|l|}{ CRP-SAA } \\
\hline High level & 33.1 & - & 21.48 & - & - & - \\
\hline Low level & 14.9 & - & 14.15 & - & - & - \\
\hline$H R$ & 2.181 & 1.999 & 1.808 & 2.744 & 2.613 & 2.209 \\
\hline $95 \% \mathrm{Cl}$ & $1.641-2.897$ & $1.070-3.737$ & $1.307-2.500$ & $1.810-4.161$ & $1.211-5.635$ & $1.336-3.652$ \\
\hline$P$ value & $<0.001$ & 0.026 & $<0.001$ & $<0.001$ & 0.01 & 0.001 \\
\hline \multicolumn{7}{|l|}{ Total SAA } \\
\hline High level & 30.25 & - & 21.04 & - & - & - \\
\hline Low level & 16.46 & - & 14.6 & - & - & - \\
\hline$H R$ & 1.697 & 1.27 & 1.631 & 1.775 & 0.44 & 1.602 \\
\hline $95 \% \mathrm{Cl}$ & $1.281-2.248$ & $0.692-2.331$ & $1.180-2.255$ & $1.243-2.533$ & $0.105-1.851$ & $1.079-2.378$ \\
\hline$P$ value & $<0.001$ & 0.436 & 0.002 & 0.001 & 0.246 & 0.016 \\
\hline \multicolumn{7}{|l|}{ CRP } \\
\hline High level & 30.59 & - & 21.35 & - & - & - \\
\hline Low level & 15.68 & - & 14.15 & - & - & - \\
\hline$H R$ & 2.03 & 1.565 & 1.794 & 2.185 & 1.64 & 1.874 \\
\hline $95 \% \mathrm{Cl}$ & $1.529-2.696$ & $0.828-2.959$ & $1.299-2.477$ & $1.534-3.112$ & $0.774-3.474$ & $1.238-2.836$ \\
\hline$P$ value & $<0.001$ & 0.162 & $<0.001$ & 0.001 & 0.189 & 0.002 \\
\hline
\end{tabular}

Abbreviations as in previous Tables." -" indicates that the cumulative survival rate is below 50\%. For grouping, the cutoff OD value for CRP-SAA is 0.10; the cutoff OD value for total SAA is 0.17 ; and the cutoff value of CRP is $8 \mathrm{mg} / \mathrm{L}$.

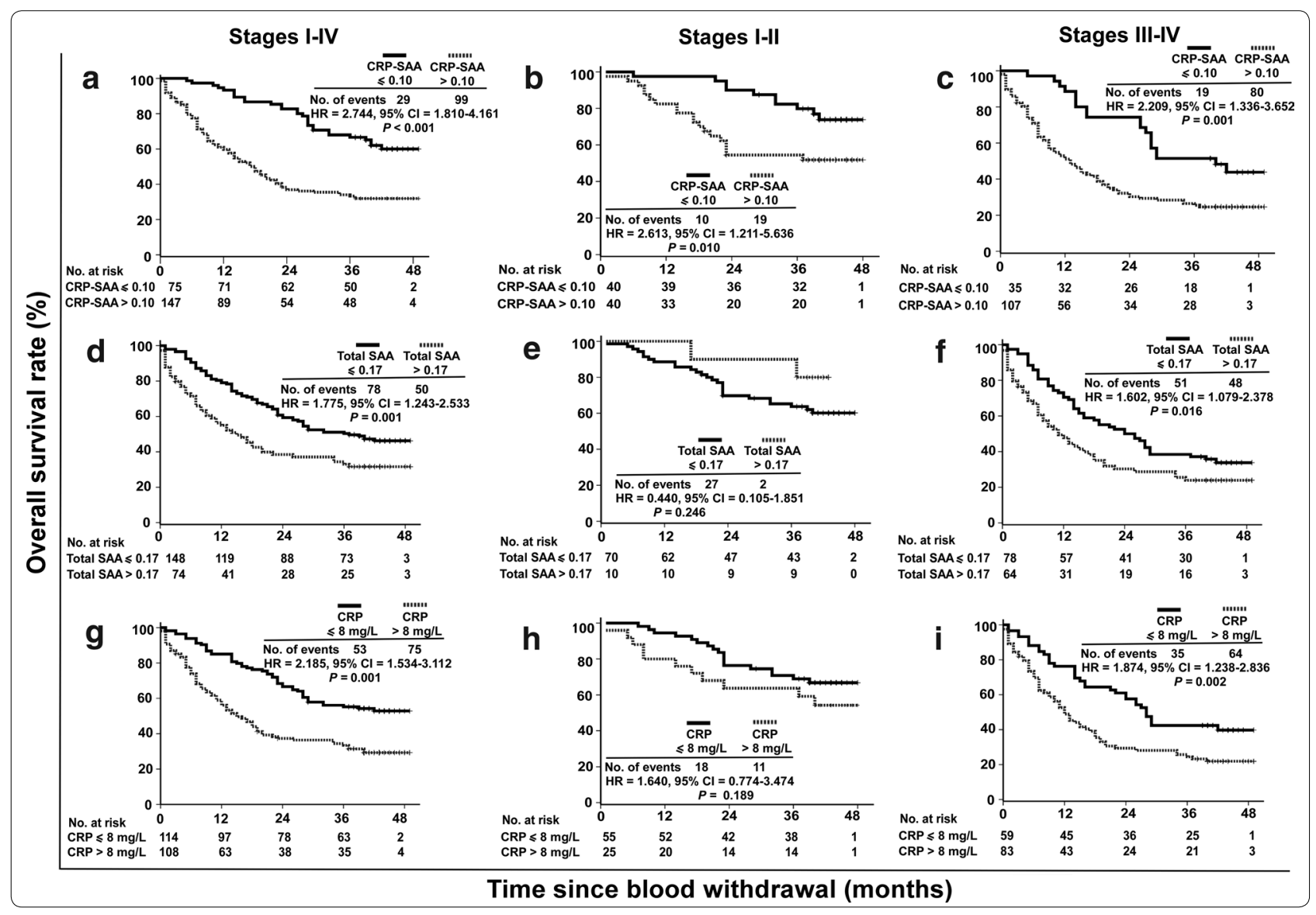


(See figure on previous page.)

Fig. 5 Prognostic values of serum CRP-SAA, total SAA, and CRP in the prospective cohort of lung cancer patients. a Kaplan-Meier survival curves of the 222 patients divided by the cutoff OD value for CRP-SAA into low- and high-level groups. b Survival curves of 80 patients at stages I-II divided by the cutoff value for CRP-SAA into low- and high-level groups. c Survival curves of 142 patients at stages III-IV divided by the cutoff value for CRP-SAA into low- and high-level groups. d Survival curves of the 222 patients divided by the cutoff OD value for total SAA into low- and high-level groups. Survival curves of 80 patients at stages I-II divided by the cutoff value for total SAA into low- and high-level groups. f Survival curves of 142 patients at stages III-IV divided by the cutoff value for total SAA into low- and high-level groups. $\mathbf{g}$ Survival curves of the 222 patients divided by the cutoff value for CRP into low- and high-level groups. h Survival curves of 80 patients at stages I-II divided by the cutoff value for CRP into lowand high-level groups. i Survival curves of 142 patients at stages III-IV divided by the cutoff value for CRP into low- and high-level groups.

Table 5 Univariate and Multivariate Cox regression analysis of potential prognostic factors for 464 lung cancer patients

\begin{tabular}{|c|c|c|c|c|c|c|}
\hline \multirow[t]{2}{*}{ Variable } & \multicolumn{3}{|c|}{ Univariate model } & \multicolumn{3}{|c|}{ Multivariate model } \\
\hline & HR & $95 \% \mathrm{Cl}$ & $P$ & HR & $95 \% \mathrm{Cl}$ & $P$ \\
\hline Age & & & & - & - & - \\
\hline$<60$ years & 1.000 & & & & & \\
\hline$\geq 60$ years & 1.151 & $0.926-1.432$ & 0.206 & & & \\
\hline Sex & & & & - & - & - \\
\hline Female & 1.000 & & & & & \\
\hline Male & 1.285 & $0.997-1.657$ & 0.053 & & & \\
\hline \multicolumn{7}{|l|}{ Smoking status } \\
\hline No & 1.000 & & & 1.000 & & \\
\hline Yes & 1.533 & $1.224-1.919$ & $<0.001$ & 1.462 & $1.080-1.980$ & 0.014 \\
\hline \multicolumn{7}{|l|}{ Treatment } \\
\hline Multimodality therapy without operation & 1.000 & & & 1.000 & & \\
\hline Operation alone & 0.231 & $0.173-0.309$ & $<0.001$ & 0.568 & $0.367-0.880$ & 0.011 \\
\hline Operation and multimodality therapy & 0.326 & $0.250-0.425$ & $<0.001$ & 0.492 & $0.362-0.669$ & $<0.001$ \\
\hline \multicolumn{7}{|l|}{ Tstage } \\
\hline $\mathrm{T} 1$ & 1.000 & & & 1.000 & & \\
\hline $\mathrm{T} 2$ & 1.176 & $0.820-1.686$ & 0.378 & 1.081 & $0.753-1.552$ & 0.671 \\
\hline T3 & 2.019 & $1.382-2.951$ & $<0.001$ & 1.352 & $0.920-1.987$ & 0.124 \\
\hline $\mathrm{T} 4$ & 2.162 & $1.436-3.253$ & $<0.001$ & 1.013 & $0.668-1.536$ & 0.951 \\
\hline \multicolumn{7}{|l|}{$\mathrm{N}$ stage } \\
\hline No & 1.000 & & & 1.000 & & \\
\hline N1 & 1.043 & $0.730-1.489$ & 0.817 & 0.789 & $0.549-1.133$ & 0.199 \\
\hline N2 & 1.756 & $1.346-2.293$ & $<0.001$ & 0.797 & 0.599-1.058 & 0.117 \\
\hline N3 & 2.725 & $1.958-3.793$ & $<0.001$ & 1.155 & $0.816-1.636$ & 0.416 \\
\hline \multicolumn{7}{|l|}{ M stage } \\
\hline Mo & 1.000 & & & 1.000 & & \\
\hline M1 & 3.091 & $2.448-3.902$ & $<0.001$ & 0.985 & $0.681-1.424$ & 0.936 \\
\hline \multicolumn{7}{|l|}{ Clinical stage } \\
\hline I & 1.000 & & & 1.000 & & \\
\hline$\|$ & 3.742 & $2.213-6.325$ & $<0.001$ & 3.254 & $1.909-5.546$ & $<0.001$ \\
\hline III & 5.267 & $3.239-8.563$ & $<0.001$ & 3.435 & $2.013-5.864$ & $<0.001$ \\
\hline IV & 11.25 & $6.855-18.461$ & $<0.001$ & 5.685 & $3.063-10.549$ & $<0.001$ \\
\hline \multicolumn{7}{|l|}{ CRP-SAA } \\
\hline Low level & 1.000 & & & 1.000 & & \\
\hline High level & 2.097 & $1.673-2.628$ & $<0.001$ & 1.545 & $1.223-1.951$ & $<0.001$ \\
\hline \multicolumn{7}{|l|}{ Total SAA } \\
\hline Low level & 1.000 & & & 1.000 & & \\
\hline High level & 1.778 & $1.429-2.212$ & $<0.001$ & 1.329 & $1.061-1.663$ & 0.013 \\
\hline \multicolumn{7}{|l|}{ CRP } \\
\hline Low level & 1.000 & & & 1.000 & & \\
\hline High level & 2.045 & $1.641-2.549$ & $<0.001$ & 1.454 & $1.156-1.829$ & 0.001 \\
\hline
\end{tabular}

\footnotetext{
"-", age and sex are not included in the Multivariate Cox regression analysis. Other footnotes as in Table 4.
} 
Table 6 Stratified Cox regression analysis of CRP-SAA, Total SAA, and CRP for 464 lung cancer patients

\begin{tabular}{|c|c|c|c|c|c|c|}
\hline \multirow[t]{2}{*}{ Variable } & \multicolumn{3}{|c|}{ Univariate model } & \multicolumn{3}{|c|}{ Multivariate model $^{\mathrm{a}}$} \\
\hline & HR & $95 \% \mathrm{Cl}$ & $P$ & HR & $95 \% \mathrm{Cl}$ & $P$ \\
\hline \multicolumn{7}{|l|}{ Stages I-II } \\
\hline \multicolumn{7}{|l|}{ CRP-SAA } \\
\hline Low level & 1.000 & & & 1.000 & & \\
\hline High level & 2.583 & $1.873-3.560$ & $<0.001$ & 1.677 & $1.188-2.368$ & 0.003 \\
\hline \multicolumn{7}{|l|}{ Total SAA } \\
\hline Low level & 1.000 & & & 1.000 & & \\
\hline High level & 1.581 & $1.164-2.150$ & 0.003 & 1.180 & $0.859-1.620$ & 0.307 \\
\hline \multicolumn{7}{|l|}{ CRP } \\
\hline Low level & 1.000 & & & 1.000 & & \\
\hline High level & 2.113 & $1.563-2.857$ & $<0.001$ & 1.429 & $1.036-1.971$ & 0.063 \\
\hline \multicolumn{7}{|l|}{ Stages III-IV } \\
\hline \multicolumn{7}{|l|}{ CRP-SAA } \\
\hline Low level & 1.000 & & & 1.000 & & \\
\hline High level & 1.899 & $1.483-2.431$ & $<0.001$ & 1.594 & $1.237-2.052$ & $<0.001$ \\
\hline \multicolumn{7}{|l|}{ Total SAA } \\
\hline Low level & 1.000 & & & 1.000 & & \\
\hline High level & 1.879 & $1.485-2.377$ & $<0.001$ & 1.359 & $1.065-1.735$ & 0.014 \\
\hline \multicolumn{7}{|l|}{ CRP } \\
\hline Low level & 1.000 & & & 1.000 & & \\
\hline High level & 1.970 & $1.554-2.499$ & $<0.001$ & 1.507 & $1.178-1.929$ & 0.001 \\
\hline
\end{tabular}

a Each serum marker was analyzed separately in the model, adjusting for age, sex, smoking status, clinical stage, and treatment. Abbreviations as in previous tables.

of SAA in the context of tumorigenesis include binding to extracellular matrix (ECM) components [25], enhancing plasminogen activation [26], and stimulating matrix metalloproteinase (MMP) production [27]. A recent study reported that the overexpression of SAA could promote Lewis lung carcinoma cell metastasis and lung colonization in animal models and that the expression of SAA was induced when lung cancer cells were cocultured with macrophages or cytokines [28]. De Santo et al. [18] reported that melanoma cells produce SAA, which facilitates tumor growth by inducing neutrophils to secrete interleukin-10 (IL-10), resulting in a suppressive immune response. Because CRP can recognize both Fc $\alpha$ receptor I (Fc $\alpha$ RI) and Fc $\gamma$ receptor (Fc $\gamma R$ ) on macrophages, we presume that the CRP-SAA complex could help SAA to bind to macrophages and induce suppressive immune responses or promote MMP production. These properties may increase the importance of SAA or CRP-SAA in tumor pathogenesis and metastasis. In our study, we also found that SAA was highly expressed in lung cancer tissues; therefore, we presume that circulating CRP may easily contact SAA produced by lung cancer cells to form the CRP-SAA complex, and the appearance of CRP-SAA in the serum could be a predictive biomarker for lung cancer progression. Moreover, high serum levels of CRP-SAA but not total SAA or CRP in the present study were significantly associated with a worse prognosis in patients with early-stage lung cancer, suggesting that the elevation of serum CRP-SAA levels may result from both the increased production of SAA in the tumor microenvironment and the elevated production of CRP by the liver in response to the chronic inflammation of the tumor site in early stages. Therefore, CRP-SAA levels could be considered a more sensitive and relevant indicator of early lung cancer progression than CRP or SAA alone.

In addition to lung cancer, elevated levels of CRP and SAA have been observed in other types of cancer, including gastric cancer [29], esophageal squamous cell carcinoma [18], and breast cancer [30]. It would thus be interesting to determine whether CRP-SAA could serve as a potential prognostic marker in these cancers. Moreover, for potential clinical application, it is important to determine whether the elevated CRP-SAA level is restricted to cancer patients or whether it is associated with other chronic inflammatory diseases.

In conclusion, the present study reveals that serum CRP-SAA isolated from serum CRP-bound complexes is a potential marker for poor prognosis in lung cancer patients. The prognostic value of CRP-SAA is higher than 
that of CRP and SAA individually, especially for earlystage lung cancer patients.

\section{Authors' contributions}

$X-Y Z$ participated in the study design, carried out the identification of complex, performed the statistical analysis, and drafted the manuscript. GZ carried out the identification of complex and performed enzyme-linked immunosorbent assay (ELISA). YJ carried out proteomics experiments and analysis. $\mathrm{DL}$ carried out the immunohistochemical assay. M-ZL and QZ carried out the selection and collection of serum samples. S-QZ carried out the analysis of clinical data. W-LL and M-SZ conceived of the study, participated in its design and coordination, and helped to draft the manuscript. All authors read and approved the final manuscript.

\section{Author details}

${ }^{1}$ State Key Laboratory of Oncology in South China, Collaborative Innovation Center for Cancer Medicine, Sun Yat-sen University Cancer Center, Guangzhou, Guangdong 510060, P.R. China. ${ }^{2}$ Department of Experimental Research, Sun Yat-sen University Cancer Center, Guangzhou, Guangdong 510060, P.R. China. ${ }^{3}$ Department of Pathogenic Biology, Guangzhou Hoffmann Institute of Immunology, School of Basic Sciences, Guangzhou Medical University, Guangzhou, Guangdong 510182, P.R. China. ${ }^{4}$ Department of Microbial and Biochemical Pharmacy, School of Pharmaceutical Sciences, Sun Yat-sen University, Guangzhou, Guangdong 510006, P.R. China. ${ }^{5}$ State Key Laboratory of Proteomics, Beijing Proteome Research Center, Beijing Institute of Radiation Medicine, Beijing 102206, P.R. China. ${ }^{6}$ Department of Clinical Laboratory, Sun Yat-sen University Cancer Center, Guangzhou, Guangdong 510060, P.R. China. ${ }^{7}$ Department of Gastrointestinal Surgery, Guangzhou Digestive Disease Center, Guangzhou First People's Hospital, Guangzhou Medical University, Guangzhou, Guangdong 510180, P.R. China.

\section{Acknowledgements}

We gratefully recognize the patients who participated in this study. This study was supported by grants from the Ministry of Science and Technology of China (2011CB504304 and 2012CB967003) and the National Natural Science Foundation of China (81271902 and 81230045).

\section{Compliance with ethical guidelines}

\section{Competing interests}

The authors declare that they have no competing interest.

Received: 4 March 2015 Accepted: 3 May 2015

Published online: 10 August 2015

\section{References}

1. Jemal A, Bray F, Center MM, Ferlay J, Ward E, Forman D. Global cancer statistics. CA Cancer J Clin. 2011;61 (2):69-90.

2. Ferlay J, Shin HR, Bray F, Forman D, Mathers C, Parkin DM. Estimates of worldwide burden of cancer in 2008: GLOBOCAN 2008. Int J Cancer. 2010;127(12):2893-917.

3. Chen WQ, Zheng RS, Zhang SW, Zeng HM, Zou XN. The incidences and mortalities of major cancers in China, 2010. Chin J Cancer. 2014;33(8):402-5.

4. Chen W, Zheng R, Zhang S, Zhao P, Li G, Wu L, et al. The incidences and mortalities of major cancers in China, 2009. Chin J Cancer. 2013;32(3):106-12.

5. Sudhindra A, Ochoa R, Santos ES. Biomarkers, prediction, and prognosis in non-small-cell lung cancer: a platform for personalized treatment. Clin Lung Cancer. 2011;12(6):360-8.

6. Mantovani A, Allavena P, Sica A, Balkwill F. Cancer-related inflammation. Nature. 2008;454(7203):436-44.

7. Grivennikov SI, Greten FR, Karin M. Immunity, inflammation, and cancer. Cell. 2010;140(6):883-99.

8. Engels EA. Inflammation in the development of lung cancer: epidemiological evidence. Expert Rev Anticancer Ther. 2008;8(4):605-15.

9. Cho WC, Kwan CK, Yau S, So PP, Poon PC, Au JS. The role of inflammation in the pathogenesis of lung cancer. Expert Opin Ther Targets. 2011;15(9):1127-37.
10. Koch A, Fohlin H, Sorenson S. Prognostic significance of C-reactive protein and smoking in patients with advanced non-small cell lung cancer treated with first-line palliative chemotherapy. J Thorac Oncol. 2009:4(3):326-32.

11. Lee JG, Cho BC, Bae MK, Lee CY, Park IK, Kim DJ, et al. Preoperative C-reactive protein levels are associated with tumor size and lymphovascular invasion in resected non-small cell lung cancer. Lung Cancer. 2009;63(1):106-10.

12. Chaturvedi AK, Caporaso NE, Katki HA, Wong HL, Chatterjee N, Pine SR, et al. C-reactive protein and risk of lung cancer. J Clin Oncol. 2010;28(16):2719-26.

13. Suresh MV, Singh SK, Agrawal A. Interaction of calcium-bound C-reactive protein with fibronectin is controlled by $\mathrm{pH}$ : in vivo implications. J Biol Chem. 2004;279(50):52552-7.

14. Yang J, Wezeman $M$, Zhang $X$, Lin $P$, Wang $M$, Qian J, et al. Human C-reactive protein binds activating Fcgamma receptors and protects myeloma tumor cells from apoptosis. Cancer Cell. 2007;12(3):252-65.

15. McArdle PA, McMillan DC, Sattar N, Wallace AM, Underwood MA. The relationship between interleukin-6 and C-reactive protein in patients with benign and malignant prostate disease. Br J Cancer. 2004;91 (10):1755-7.

16. Black S, Kushner I, Samols D. C-reactive protein. J Biol Chem. 2004;279(47):48487-90.

17. Cho WC, Yip TT, Cheng WW, Au JS. Serum amyloid A is elevated in the serum of lung cancer patients with poor prognosis. Br J Cancer. 2010;102(12):1731-5.

18. De Santo C, Arscott R, Booth S, Karydis I, Jones M, Asher R, et al. Invariant NKT cells modulate the suppressive activity of IL-10-secreting neutrophils differentiated with serum amyloid A. Nat Immunol. 2010;11(11):1039-46.

19. Cocco E, Bellone S, El-Sahwi K, Cargnelutti M, Casagrande F, Buza N, et al. Serum amyloid A (SAA): a novel biomarker for uterine serous papillary cancer. Br J Cancer. 2009;101 (2):335-41.

20. Findeisen P, Zapatka M, Peccerella T, Matzk H, Neumaier M, Schadendorf $D$, et al. Serum amyloid $A$ as a prognostic marker in melanoma identified by proteomic profiling. J Clin Oncol. 2009;27(13):2199-208.

21. Kimura M, Tomita Y, Imai T, Saito T, Katagiri A, Ohara-Mikami Y, et al. Significance of serum amyloid $A$ on the prognosis in patients with renal cell carcinoma. Cancer. 2001;92(8):2072-5.

22. Cocco E, Bellone S, El-Sahwi K, Cargnelutti M, Buza N, Tavassoli FA, et al. Serum amyloid A: a novel biomarker for endometrial cancer. Cancer. 2010;116(4):843-51.

23. Planque C, Kulasingam V, Smith CR, Reckamp K, Goodglick L, Diamandis EP. Identification of five candidate lung cancer biomarkers by proteomics analysis of conditioned media of four lung cancer cell lines. Mol Cell Proteomics. 2009;8(12):2746-58.

24. Cremona M, Calabro E, Randi G, De Bortoli M, Mondellini P, Verri C, et al. Elevated levels of the acute-phase serum amyloid are associated with heightened lung cancer risk. Cancer. 2010;116(5):1326-35.

25. Preciado-Patt L, Levartowsky D, Prass M, Hershkoviz R, Lider O, Fridkin M. Inhibition of cell adhesion to glycoproteins of the extracellular matrix by peptides corresponding to serum amyloid A. Toward understanding the physiological role of an enigmatic protein. Eur J Biochem. 1994;223(1):35-42.

26. Michaeli A, Finci-Yeheskel Z, Dishon S, Linke RP, Levin M, Urieli-Shoval S. Serum amyloid $A$ enhances plasminogen activation: implication for a role in colon cancer. Biochem Biophys Res Commun. 2008;368(2):368-73.

27. Lee HY, Kim MK, Park KS, Bae YH, Yun J, Park Jl, et al. Serum amyloid A stimulates matrix-metalloproteinase-9 upregulation via formyl peptide receptor like-1-mediated signaling in human monocytic cells. Biochem Biophys Res Commun. 2005;330(3):989-98.

28. Sung HJ, Ahn JM, Yoon YH, Rhim TY, Park CS, Park JY, et al. Identification and validation of SAA as a potential lung cancer biomarker and its involvement in metastatic pathogenesis of lung cancer. J Proteome Res. 2011;10(3):1383-95.

29. Sasazuki S, Inoue M, Sawada N, Iwasaki M, Shimazu T, Yamaji T, et al. Plasma levels of C-reactive protein and serum amyloid $\mathrm{A}$ and gastric cancer in a nested case-control study: Japan Public Health Center-based prospective study. Carcinogenesis. 2010;31(4):712-8.

30. Pierce BL, Neuhouser ML, Wener MH, Bernstein L, Baumgartner RN, Ballard-Barbash $\mathrm{R}$, et al. Correlates of circulating C-reactive protein and serum amyloid A concentrations in breast cancer survivors. Breast Cancer Res Treat. 2009;1 14(1):155-67. 